\title{
УЧЕТ ИЗМЕНЕНИЯ ДЕФОРМАТИВНЫХ СВОЙСТВ ДРЕВЕСИНЫ ВО ВРЕМЕНИ ПРИ ПРОЕКТИРОВАНИИ ДЕРЕВЯННЫХ КОНСТРУКЦИЙ
}

\author{
А. Я. Найчук ${ }^{1}$
}

\author{
${ }^{1}$ Д. т. н., доцент, профрессор кафедры строительных конструкций учреждения образования \\ «Брестский государственный технический университет», Брест, Беларусь, e-mail: atnya@yandex.ru
}

\begin{abstract}
Реферат
Приводится методика определения предела высокоэластичности древесины элементов деревянных конструкций покрытия зданий в зависимости от продолжительности увеличения снеговой нагрузки для климатических районов Республики Беларусь. На основании результатов расчета установлено, что для климатических районов Республики Беларусь предел высокоэластичности древесины элементов конструкций покрытия в условиях эксплуатации снижается меньше, чем ее прочность. Поэтому при проектировании деревянных конструкций покрытий зданий могут использоваться модели, учитывающие изменение деформативных свойств древесины во времени, приведенные в Еврокоде 5.
\end{abstract}

Ключевые слова: деревянные конструкции, древесина, прочность, предел высокоэластичности, нагрузка.

\section{ACCOUNTING FOR CHANGES IN THE DEFORMATIVE PROPERTIES OF TIMBER OVER TIME IN THE DESIGN OF WOODEN STRUCTURES}

\section{Abstract}

\section{A. J. Naichuk}

The article presents a method for determining the limit of high elasticity of timber elements of timber structures covering buildings, depending on the duration of the increase in snow load for the climatic regions of the Republic of Belarus. Based on the calculation results, it was found that for the climatic regions of the Republic of Belarus, the limit of high elasticity of timber of the coating structural elements under operating conditions decreases less than its strength. Therefore, when designing wooden structures for building coverings, models can be used that take into account the change in the deformative properties of timber over time, given in Eurocode 5.

Keywords: timber structures, timber, strength, high elasticity limit, load.

\section{Введение}

При проектировании деревянных конструкций изменение деформативных свойств древесины во времени учитывается путем использования частных коэффрициентов ползучести, определенных для стадии линейной ползучести материала. Так [1] изменения деформативных свойств древесины и соединений элементов конструкций во времени учитывается путем использования коэффициента

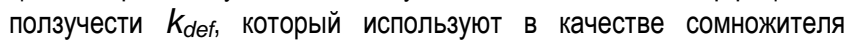
к упругим характеристикам. Величина $k_{d e f}$ зависит от продолжительности воздействия и условий эксплуатации. Следует отметить, что приведенные в [1] значения $k_{\text {def }}$ определены для линейной ползучести древесины, где увеличение деформаций во времени пропорционально увеличению напряжений, величина которых не превышает длительной прочности древесины, определенной для временного интервала 50 лет. В отличие от изотропных материалов, для древесины характер протекания ползучести во времени зависит не только от интенсивности напряжений и температуры, но и от ее влажности. Утверждение, что деформативность древесины и соединений элементов деревянных конструкций во времени зависит только от уровня напряжений по отношению к длительной прочности древесины, является лишь необходимым условием, но недостаточным. Для более полного понимания процессов деформирования древесины необходимо рассмотреть ее структуру.

Общеизвестно, что древесина является природным полимером, обладающим особыми свойствами, отличающими ее от твердых кристаллических веществ и искусственных полимеров. Сущность этих отличий заложена в самой структуре древесины. Так, рассматривая структуру древесины, можно отметить, что она состоит из целого ряда полимерных тел, где одна их часть при обычной комнатной температуре и влажности находится в высокоэластическом состоянии, а другая - в застеклованном. Основной структурной составляющей древесины является целлюлоза - высокоориентированное аморфное тело, находящееся в застеклованном состоянии. Что же касается инкрустирующих веществ, таких как лигнин, гемицеллюлоза и пенктиновые вещества, то они образуют группу тел, часть из которых находится при обычных условиях в застеклованном состоянии, а часть - высокоэластическом. Исходя из структуры древесины, входящие в нее вещества способны к проявлению вынужденных эластических десрормаций при условии, что напряжения, вызванные внешним воздействием (нагрузкой), превышают величину предела вынужденной эластичности. Согласно исследованиям [2] численное значение этого предела для различных частиц древесины различно. Таким образом, переход застеклованного полимера древесного вещества в состояние высокоэластичности происходит путем механической активации (силового воздействия), а не нагреванием (тепловой активацией) выше температуры стеклования, как это происходит в искусственных полимерах [3, 4]. В работе [5] было установлено, что представление о нелинейных деформациях древесины [6] при напряжениях выше предела высокоэластичности (II область деформирования) не связаны с деструктивным процессом, т. е. накоплением в материале повреждений. Исходя из этого, существенная роль нелинейных вынужденных высокоэластических деформаций древесины во II области при сопротивлении конструкций внешним воздействиям обусловлена лишь той значительной величиной, которая может быть достигнута по мере их развития без повышения напряжений. Поскольку величина предела вынужденной высокоэластичности $\sigma_{в э}$ соответствует моменту, когда скорость деформирования испытываемого образца сравнялась со скоростью релаксационных процессов, происходящих в древесине на молекулярном уровне при данной температуре и влажности, то с возрастанием скорости деформации величина $\sigma_{в э}$ увеличивается, т. е. не является постоянной величиной. При напряжениях $\sigma<\sigma_{в э}$ в древесине испытываемого образца наблюдается только упругая деформация и обратимая десрормация ползучести [7].

Согласно [2] механизм образования деформаций ползучести древесины обусловлен тем, что в инкрустирующих веществах, находящихся в высокоэластическом состоянии, упругая десормация постепенно замещается эластической, поскольку в начальной стадии деформирования свободное проявление эластической деформации стеснено параллельно соединенными частицами, находящимися 
Вестник Брестского государственного технического университета. 2021

в застеклованном состоянии. С уменьшением упругой деформации одновременно происходит релаксация напряжений. Если внешняя нагрузка остается постоянной, то падению напряжений в одних частицах будет соответствовать возрастание напряжений и упругой десормации в других (в целлюлозе), и как результат - деформация всего образца. Процесс ползучести (увеличения деформаций) будет происходить до тех пор, пока в инкрустирующих высокоэластических веществах напряжение не уменьшиться до нуля, т. е. высокоэластическая деформация в них целиком заменит упругую, а напряжение в веществах, находящихся в застеклованном состоянии, не достигнет своего наибольшего значения [2]. Процессы ползучести и релаксации напряжений в древесине происходят одновременно и зависят от скорости приложения напряжений. При значениях напряжений $\sigma \geq \sigma_{\text {вэ }}$, постоянно действующих в древесине образца или элементе конструкции, наряду с упругой деформацией и обратимой деформацией ползучести возникает необратимая деформация ползучести, величина которой тем больше, чем больше уровень напряжений. Возникновение остаточных деформаций объясняется тем, что в данном случае часть инкрустирующих веществ, находящихся

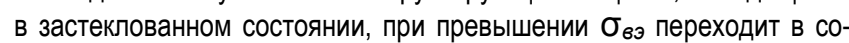
стояние вынужденной эластичности, и в них со временем часть упругой деформации замещается деформацией вынужденной эластичности, а напряжение начинает уменьшаться [2]. Такие процессь деформирования характерны для всех видов напряженного состояния древесины, за исключением растяжения поперек волокон, где целлюлоза не переходит в состояние вынужденной эластичности, независимо от величины напряжений.

Исследованиям ползучести и релаксации напряжений посвящены работы [8-11], а теории десоормирования древесины как полимерного тела органического происхождения - работы $[2,5]$. Установлено, что сопротивление древесины внешним воздействиям зависит не только от их величины, но и скорости приложения $[2,6,8-13]$ Согласно исследованиям [8-13] процесс деформирования и прочность древесины зависят от скорости нагружения. При увеличении скорости нагружения прочность древесины увеличивается, а величина деформации разрушения - уменьшается.

В процессе эксплуатации деревянных конструкций деформирование древесины во времени зависит от вида напряженного состояния, уровня напряжений и условий эксплуатации. Установлено, что при деформировании древесины во времени характерны две области: линейная зависимость деформаций и нелинейная. Величину напряжений, соответствующих переходу от одной (I) области во вторую (II) называют пределом высокоэластичности. Ранее эта граница именовалась пределом пластического течения [6] как для твердых кристаллических веществ. Такое изменение термина, введенного Ю. М. Ивановым, базируется на результатах его исследований [5], позволивших сформулировать новые представления относительно природы деформирования древесины во ІІ-ой области, которые не связаны с деструктивным процессом, т. е. накоплением повреждений. Кроме того, учитывая результаты исследований [5] в деревянных конструкциях, находящихся в процессе эксплуатации, существенная роль нелинейных вынужденных высокоэластических

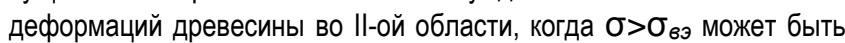
достигнута по мере их развития без повышения напряжений.

Таким образом, древесина элементов деревянных конструкций, находящихся в эксплуатации, может находиться как І-ой, так и II-ой области деформирования в зависимости от климатического района, скорости увеличения нагрузки и температурно-влажностных условий окружающей среды.

Целью данной работы являлось выявление величин напряжений, соответствующих переходу от І-ой (линейно-упругой) области деформирования древесины элементов деревянных конструкций во II-ую (нелинейную) в зависимости от климатического района Республики Беларусь.

\section{Основная часть}

Общеизвестно, что за величину предела вынужденной высокоэластичности $\sigma_{в э}$ принимается такое значение напряжения, при котором скорость деформирования испытуемого образца равна скорости релаксационных процессов, происходящих в веществах древесины на молекулярном уровне при постоянной температуре и влажности. Поскольку древесина состоит из веществ, часть из которых находится в застеклованном состоянии, а другая - в высокоэластическом, то и процессы их дефрормирования от внешних воздействий будут происходить по-разному. С увеличением скорости нагружения предел высокоэластичности увеличивается из-за того, что скорость нагружения в течение определенного времени превышает скорость перераспределения усилий между структурными элементами древесины на молекулярном уровне.

Для определения зависимости предела высокоэластичности $\sigma_{в э}$ от скорости нагружения обычно используют стандартные образцы, применяемые при определении прочности древесины для соответствующего вида напряженного состояния. С практической точки зрения наибольший интерес представляет зависимость предела высокоэл астичности от скорости нагружения при сжатии древесины вдоль волокон, поскольку для данного вида напряженного состояния наиболее характерно две области деформирования древесины. Данный вид напряженного состояния характерный для древесины изгибаемых и сжато изгибаемых элементов конструкций, а также сжатых, изгибаемых и сжато-изгибаемых стыков элементов деревянных конструкций.

В работе [14] было установлено, что предел высокоэластичности $\sigma_{в э}$ зависит от скорости нагружения испытываемого образца. При увеличении скорости нагружения образца $\sigma_{в ə}$ возрастает по сравнению со значением, полученным при стандартной скорости, установленной в соответствующих стандартах [15] по определению прочности древесины независимо от класса ее прочности.

Для элементов конструкций, находящихся в эксплуатации, вели-

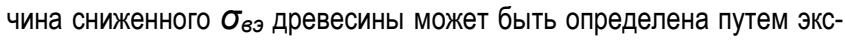
траполяции зависимости $\sigma_{\text {вэ }}$ от времени релаксации $t_{r}$, определенного при испытаниях стандартных образцов с разной скоростью нагружения.

В результате аппроксимации данных, приведенных в работе [14],

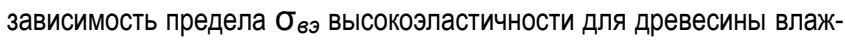
ностью 15 \% может быть описана следующим выражением:

$$
\sigma_{6 э, 15}=68,59-1,38 \cdot \lg t_{r}
$$

где $\sigma_{6 э, 15}$ - предел высокоэластичности при влажности древесины $15 \%$, Мпа;

\section{$t_{r}$ - время релаксации, с.}

В выражении (1) время релаксации $t_{r}$ определялось из выражения (2)

$$
t_{r}=\frac{1}{v_{\varepsilon}},
$$

где $v_{\varepsilon}$ - скорость роста деформаций, $\mathrm{c}^{-1}$.

Скорость деформаций при испытании образцов для І-ой области деформирования древесины определялась из выражения

$$
v_{\varepsilon} \approx \frac{v_{\sigma}}{E_{l, \text { mean }}},
$$

здесь $V_{\sigma}$ - скорость роста напряжений при испытании образца, МПа/с;

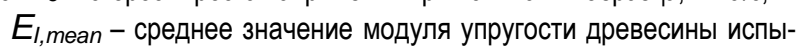
тываемого образца в І-ой области деформирования, МПа.

Согласно [1] деревянные конструкции покрытий и перекрытий могут быть подвержены действию постоянных, длительных, среднесрочных и кратковременных нагрузок. Наиболее значимыми по степени влияния на величины прочностных и упругих характеристик древесины во времени являются нагрузки, относящиеся к постоянным, длительным и среднесрочным. При определении расчетных значений постоянных нагрузок [16] частный коэффициент $\mathrm{Y}_{G}=1,35$, а для переменных $-Y_{Q}=1,5$.

Деревянные конструкции в покрытиях зданий на территории Республики Беларусь подвержены воздействиям постоянных $\Sigma G_{i}$ (собственная масса конструкций покрытия), среднесрочной $Q_{1}$ 
Вестник Брестского государственного технического университета. 2021

(снеговой) и кратковременной $Q_{2}$ (ветровой) нагрузок. Анализируя величины отношения расчетных значений среднесрочной (снеговой) $Q_{1 d}$ к расчетному значению полной нагрузки $F_{d}$, действующей на покрытия зданий в климатических зонах Республики Беларусь, необходимо отметить, что их величина находится в пределах от 0,4 до 0,6. Согласно исследованиям [17] максимальная продолжительность $t_{Q 1}$ увеличения снегового покрова на покрытии зданий за 70 лет метеонаблюдений для районов Брестской области составила 2,8 месяца, Минской области - 3,6 месяца, Витебской и Могилевской областей - 4 месяца. Скорость роста напряжений $V_{\sigma, Q 1}$ и десормаций $v_{\varepsilon, Q 1}$ от нарастания снеговой нагрузки за время $t_{Q 1}$ для элементов конструкций определим по формулам

$$
\begin{gathered}
v_{\sigma, Q 1}=\frac{f_{d} \cdot\left(Q_{1 d} / F_{d}\right)}{t_{Q 1}} ; \\
v_{\varepsilon, Q 1} \approx \frac{v_{\sigma, Q 1}}{E_{\text {mean }}},
\end{gathered}
$$

где $f_{d}$ - расчетное значение прочности древесины для соответствующего класса прочности и сочетания воздействий, МПа;

$Q_{1 d}$ - расчетное значение снеговой нагрузки на покрытие, МПа;

$F_{d}$ - расчетное значение нагрузки на покрытие здания, МПа;

$t_{Q 1}$ - продолжительность нарастания снеговой для соответствующего климатического района, с;

$E_{\text {mean }}$ - среднее значение модуля упругости древесины, МПа, принимаемое для пиломатериалов из таблицы 1 , а для клееной древесины - таблицы 2.
Согласно [1]

$$
f_{d,(G+Q 1)}=\frac{f_{k} \cdot k_{\mathrm{mod},(G+Q 1)}}{\gamma_{M}},
$$

где $f_{d,(G+Q 1)}$ - расчетное значение прочности древесины конструкций покрытия при совместном действии постоянной и снеговой (среднесрочной) нагрузок, МПа;

$f_{k}$ - характеристическое значение прочности древесины, принимаемое для пиломатериалов из таблицы 1, а для клееной древесины - таблица 2, МПа;

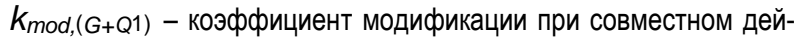
ствии на покрытие постоянной и снеговой нагрузок, принимаемый в соответствии с требованиями [1];

Үм- частный коэффициент свойств материалов и изделий, значение которого согласно [1] для пиломатериалов составляет 1,3, а для клееной древесины - 1,25.

Используя данные в таблице 1 и таблице 2 и выражения (2), (4), (5), были определены значения скорости роста напряжений $V_{\sigma, Q 1}$ и деформаций $v_{\varepsilon, Q 1}$, время релаксации $t_{r}$, и предел высокоэластич-

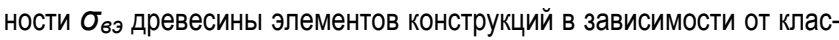
са прочности, величины $Q_{1 d} / F_{d}$ и продолжительности $t_{Q 1}$ роста снегового покрова на покрытии здания для климатических районов Республики Беларусь. Результаты выполненных расчетов приведены в таблице 3 и таблице 4.

\begin{tabular}{|c|c|c|c|c|c|c|c|c|}
\hline Класс прочности по [18] & $\mathrm{C} 14$ & $\mathrm{C} 18$ & $\mathrm{C} 22$ & $\mathrm{C} 27$ & C35 & C45 & D50 & D70 \\
\hline $\begin{array}{l}\text { Характеристическое значение прочности } \\
\text { при сжатии вдоль волокон, } f_{c, k} \text { по [18], H/мм² }\end{array}$ & 16 & 18 & 20 & 22 & 25 & 27 & 29 & 34 \\
\hline $\begin{array}{l}\text { Расчетное значение прочности } \\
\text { при сжатии вдоль волокон } f_{c, d}, \mathrm{H} / \text { мм² }^{2}\end{array}$ & 9,85 & 11,08 & 12,31 & 13,54 & 15,38 & 16,62 & 17,85 & 20,92 \\
\hline $\begin{array}{l}\text { Среднее значение модуля упругости } \\
\text { вдоль волокон } E_{\text {mean }} \text { по [18], Н/мм² }\end{array}$ & 7000 & 9000 & 10000 & 11000 & 13000 & 15000 & 14000 & 20000 \\
\hline
\end{tabular}

Таблица 1 - Характеристические и расчетные значения прочности, а также модуля упругости древесины элементов конструкций, изготовленных из пиломатериалов некоторых классов прочности

\begin{tabular}{|c|c|c|c|c|c|c|c|c|}
\hline Класс прочности & GL20h & GL24h & GL28h & GL32h & GL22c & GL24c & GL28c & GL32c \\
\hline $\begin{array}{l}\text { Характеристическое значение прочности } \\
\text { при сжатии вдоль волокон } f_{c, k} \text { по [19], H/мм² }\end{array}$ & 20 & 24 & 28 & 32 & 20 & 21,5 & 24 & 25,5 \\
\hline $\begin{array}{l}\text { Расчетное значение прочности } \\
\text { при сжатии вдоль волокон } f_{c, q, d}, \mathrm{H} / \mathrm{Mm}^{2}\end{array}$ & 12,8 & 15,36 & 17,92 & 20,48 & 12,8 & 13,76 & 15,36 & 16,32 \\
\hline $\begin{array}{l}\text { Среднее значение модуля упругости вдоль } \\
\text { волокон } E_{0, q, \text { mean }} \text { по [19], } \mathrm{H} / \mathrm{Mm}^{2}, \mathrm{H} / \mathrm{Mm}^{2}\end{array}$ & 8400 & 11500 & 12600 & 14200 & 10400 & 11000 & 12500 & 13500 \\
\hline
\end{tabular}

Таблица 2 - Характеристические и расчетные значения прочности, а также модуля упругости древесины элементов конструкций, изготовленных из клееной древесины некоторых классов прочности

\begin{tabular}{|c|c|c|c|c|c|c|c|c|}
\hline Класс прочности & C14 & C18 & $\mathrm{C} 22$ & $\mathrm{C} 27$ & C35 & $\mathrm{C} 45$ & D50 & D50 \\
\hline \multicolumn{9}{|c|}{ Брестская область, $t_{Q 1}=7257600 \mathrm{c}$} \\
\hline $\begin{array}{l}\text { Предел высокоэластичности } \sigma_{\text {вэ древесины }} \\
\text { при сжатии элементов конструкций для } Q_{1 d} / F_{d}=0,4, \mathrm{MПа}\end{array}$ & 54,64 & 54,56 & 54,56 & 54,56 & 54,53 & 54,49 & 54,58 & 54,46 \\
\hline $\begin{array}{l}\text { Предел высокоэластичности } \sigma_{в э} \text { древесины } \\
\text { при сжатии элементов конструкций для } Q_{1 d} / F_{d}=0,6, \mathrm{MПа}\end{array}$ & 54,88 & 54,80 & 54,80 & 54,80 & 54,78 & 54,74 & 54,82 & 54,70 \\
\hline \multicolumn{9}{|c|}{ Минская область, $t_{Q 1}=9331200 \mathrm{c}$} \\
\hline $\begin{array}{l}\text { Предел высокоэластичности } \sigma_{в э} \text { древесины } \\
\text { при сжатии элементов конструкций для } Q_{1 d} / F_{d}=0,4, \mathrm{MПа}\end{array}$ & 54,49 & 54,41 & 54,42 & 54,41 & 54,38 & 54,34 & 54,43 & 54,31 \\
\hline $\begin{array}{l}\text { Предел высокоэластичности } \sigma_{в э} \text { древесины } \\
\text { при сжатии элементов конструкций для } Q_{1 d} / F_{d}=0,6, \mathrm{MПа}\end{array}$ & 54,73 & 54,65 & 54,65 & 54,65 & 54,63 & 54,59 & 54,67 & 54,55 \\
\hline \multicolumn{9}{|c|}{ Витебская и Могилевская области, $t_{Q 1}=10368000 \mathrm{c}$} \\
\hline $\begin{array}{l}\text { Предел высокоэластичности } \sigma_{\text {вэ древесины }} \\
\text { при сжатии элементов конструкций для } Q_{1 d} / F_{d}=0,4, \mathrm{MПа}\end{array}$ & 54,42 & 54,34 & 54,34 & 54,34 & 54,32 & 54,28 & 54,36 & 54,25 \\
\hline $\begin{array}{l}\text { Предел высокоэластичности } \sigma_{в э} \text { древесины } \\
\text { при сжатии элементов конструкций для } Q_{1 d} / F_{d}=0,6, \text { МПа }\end{array}$ & 54,67 & 54,59 & 54,59 & 54,59 & 54,56 & 54,52 & 54,61 & 54,49 \\
\hline
\end{tabular}

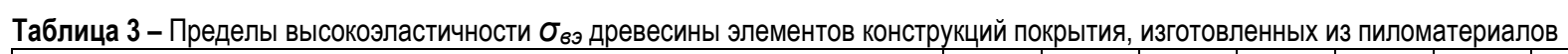


Вестник Брестского государственного технического университета. 2021

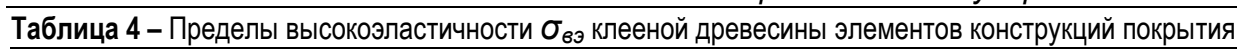

\begin{tabular}{|c|c|c|c|c|c|c|c|c|}
\hline Класс прочности & GL20h & GL24h & GL28h & GL32h & GL22c & GL24c & GL28c & GL32c \\
\hline \multicolumn{9}{|c|}{ Брестская область, $t_{Q 1}=7257600 \mathrm{c}$} \\
\hline $\begin{array}{l}\text { Предел высокоэластичности } \sigma_{s э} \\
\text { древесины при сжатии элементов } \\
\text { конструкций для } Q_{1 d} / F_{d}=0,4, \text { МПа }\end{array}$ & 54,69 & 54,61 & 54,64 & 54,65 & 54,56 & 54,57 & 54,55 & 54,56 \\
\hline $\begin{array}{l}\text { Предел высокоэластичности } \sigma_{\beta э} \\
\text { древесины при сжатии элементов } \\
\text { конструкций для } Q_{1 d} / F_{d}=0,6, \text { МПа }\end{array}$ & 54,93 & 54,85 & 54,89 & 54,90 & 54,80 & 54,81 & 54,80 & 54,79 \\
\hline \multicolumn{9}{|c|}{ Минская область, $t_{Q 1}=9331200 \mathrm{c}$} \\
\hline $\begin{array}{l}\text { Предел высокоэластичности } \sigma_{\beta э} \\
\text { древесины при сжатии элементов } \\
\text { конструкций для } Q_{1 d} / F_{d}=0,4, \text { МПа }\end{array}$ & 54,53 & 54,46 & 54,49 & 54,50 & 54,41 & 54,42 & 54,41 & 54,40 \\
\hline $\begin{array}{l}\text { Предел высокоэластичности } \sigma_{в э} \\
\text { древесины при сжатии элементов } \\
\text { конструкций для } Q_{d} / F_{d}=0,6, M П a\end{array}$ & 54,78 & 54,70 & 54,74 & 54,74 & 54,65 & 54,66 & 54,65 & 54,64 \\
\hline \multicolumn{9}{|c|}{ Витебская и Могилевская области, $t_{Q 1}=10368000 \mathrm{c}$} \\
\hline $\begin{array}{l}\text { Предел высокоэластичности } \sigma_{\beta э} \\
\text { древесины при сжатии элементов } \\
\text { конструкций для } Q_{1 d} / F_{d}=0,4, \text { МПа }\end{array}$ & 54,47 & 54,39 & 54,43 & 54,43 & 54,34 & 54,35 & 54,34 & 54,33 \\
\hline $\begin{array}{l}\text { Предел высокоэластичности } \sigma_{в э} \\
\text { древесины при сжатии элементов } \\
\text { конструкций для } Q_{1 d} / F_{d}=0,6, \text { МПа }\end{array}$ & 54,71 & 54,64 & 54,67 & 54,68 & 54,59 & 54,60 & 54,59 & 54,56 \\
\hline
\end{tabular}

Анализируя данные, приведенные в таблице 3 и таблице 4, можно отметить, что $\sigma_{8 э}$ практически не зависит от климатического района Республики Беларусь, класса прочности древесины и отношения $Q_{1 d} / F_{d}$ в рассмотренном интервале изменения. На основании данных, приведенных в таблице 3 и таблице 4, среднее значение предела высокоэластичности древесины составляет $\sigma_{6 э, Q 1, \text { mean }}=54,57 \mathrm{MПа.}$

Согласно [15] определение прочности цельной древесины осуществляется путем испытания стандартных образцов площадью поперечного сечения $A=b \times h=45 \times 70=3150$ мм² $^{2}$ а клееной -

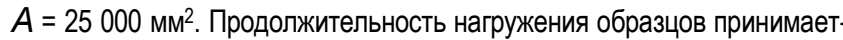
ся равной $300 \pm 120$ с. Тогда, при заданной продолжительности испытаний, скорость роста напряжений $v_{\sigma}$ в испытываемых образцах для каждого класса прочности будет разной. Для образцов из пиломатериалов она находится в интервале от 0,05 MПа/с до 0,17 MПа/c, а для образцов из клееной древесины - от 0,07 МПа/с до 0,13 МПа/с. Используя выражения (1), (2) и (3) предел высокоэластичности $\sigma_{\text {вэ,ст }}$ древесины при испытании стандартных образцов из пиломатериалов будет находиться в пределах от 61,48 МПа до 61,76 МПа, а для образцов из клееной древесины - от 61,4 МПа до 61,62 МПа. Исходя из полученных результатов расчета можно отметить, что для принятой в [15] продолжительности испытаний стандартных образцов, значения

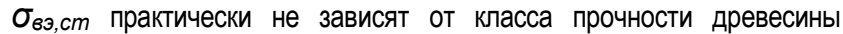
Таким образом, за величину предела высокоэластичности древесинь при испытании стандартных образцов по методике [15] может быть принято среднее значение $\sigma_{8 э, c m}$, mean $=61,57 \mathrm{MПа.}$

С целью оценки степени снижения предела высокоэластичности по сравнению с длительной прочностью древесины элементов конструкций, выполним сопоставление значений $\sigma_{\theta \ni, Q 1} / \sigma_{6 \ni, c m, \text { mean }}=0,89$ и коэфффициента модификации $k_{\text {mod. }}$. Согласно [1] при совместном действии постоянной и снеговой нагрузок на покрытие $k_{\text {mod }}=0,80$.

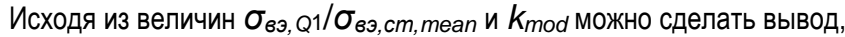
что снижение прочности древесины элементов конструкций в условиях их эксплуатации происходит быстрее, чем снижение предела высокоэластичности.

\section{Заключение}

На основании выполненных расчетов можно сделать вывод, что для климатических районов Республики Беларусь в условиях эксплуатации деревянных конструкций покрытия в древесине элемен-

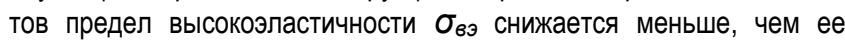
прочность, а приведенная в [1] методика учета по изменению де- формативных свойств древесины во времени, используемая при проектировании конструкций, является приемлемой. Данный вывод справедлив для элементов конструкций, в которых древесина находится в условиях одноосного или сложного однородного напряженного состояния. Что же касается элементов конструкций, древесина которых находится в условиях сложного неоднородного напряженного состояния то здесь необходимо проведение экспериментальнотеоретических исследований по разработке новых или обоснование существующих расчетных моделей, базирующихся на использовании нелинейной теории ползучести.

\section{Список цитированных источников}

1. Еврокод 5. Проектирование деревянных конструкций. Часть 1-1. Общие правила и правила для зданий : TKП ЕN 1995-1-1-2009 (02250). Введ. 01.01.10. - Минск : Минстройархитектуры, 2010. - 110 с.

2. Огарков, Б. И. Теория деформирования древесных материалов с учетом ползучести / Б. И. Огарков // Исследования в области древесины и древесных материалов Тр. Ин-та леса и древесины СО АН СССР Красноярск, 1967. - С. 130-139.

3. Кравчук, А. С. Механика полимерных и композиционных материалов. Экспериментальные и численные методы / А. С. Кравчук, В. П. Майборода, Ю. С. Уржумцев. - М.: Наука, 1985. - 304 с.

4. Нарисава, И. Прочность полимерных материалов / И. Нарисава. М.: Химия, 1987. - $400 \mathrm{c.}$

5. Иванов, Ю. М. Энергия активации развития у ориентированного жесткоцепного полимера вынужденной эластической деформации / Ю. М. Иванов // Высокомолекулярные соединения. - 1984. т. 26Б-№6. - C. 425-430.

6. Иванов, Ю. М. Предел пластического течения древесины / Ю. М. Иванов. - М. : Госстройиздат 1948. - 223 с.

7. Иванов, Ю. М. К исследованию высокоэластического состояния древесины / Ю. М. Иванов. - Тр. Ин-та леса и древесины СО АН СССР, 1962. - T. 51. - С. 78-89.

8. Белянкин, Ф.П. Длительное сопротивление дерева / Ф. П. Белянкин // ОНТИ. - М. : Наука, 1934. - 416 с.

9. Белянкин, Ф.П.Деформативность и сопротивляемость древесины / Ф. П. Белянкин, В. Ф. Яценко. - К.: Из-во АН УССР, 1957. - 86 с.

10. Уголев, Б. Н. Деформативность древесины и напряжения при сушке / Б. Н. Уголев. - М., 1971. - 174 с.

11. Леонтьев, Н. Л. Длительное сопротивление древесины / Н. Л. Леонтьев. - М. : Гослесбумиздат, 1957. -132 с.

12. Иванов, Ю. М. Длительная прочность древесины / Ю. М. Иванов // Лесн. журн. - 1972. - № 4.- С. 76-82. 
13. Огарков, Б. И. Теория упругого последействия древесины // Б. И. Огарков / «Журнал технической физики». - 1957. - Т. 27. - С. 70-82.

14. Любошиц, М. И. Влияние скорости испытания на предел пластического течения древесины сосны //Автореферат дисс., канд. техн. наук. - Минск, 1950. -16 с.

15. Конструкции деревянные. Древесина конструкционная цельная и клееная многослойная. Определение некоторых физических и механических свойств. СТБ ЕN 408-2012.- Введ. 20.04.2012 Минск. : Госстандарт, 2012 - 22 c.

16. Еврокод. Основы проектирования строительных конструкций: ТКП ЕN 1990-2011* (02250). - Введ. 15.12.11. - Минск : Минстройархитектуры, 2011. - 94 с.

17. Meshyk, A., Barushka, M, Marozava, V. (2020) Snow as a Contributor to Spring Flooding in Belarus. Environmental Science and Pollution Research. 1-11. https://doi.org/10.1007/s11356-020-09638-8.

18. Древесина конструкционная. Классы прочности. СТБ ЕN 338-2011. Введ. 28.10.2011 - Минск. : Госстандарт, 2011. - 7 с.

19. Конструкции деревянные. Древесина клееная многослойная. Классы прочности и определение характеристических значений. СТБ EN 1194-2011.- Введ. 25.11.2011 - Минск. : Госстандарт, $2011-9 \mathrm{c}$.

\section{References}

1. Evrokod 5. Proektirovanie derevyannyh konstrukcij. CHast' 1-1. Obshchie pravila i pravila dlya zdanij : TKP EN 1995-1-1-2009 (02250). Vved. 01.01.10. - Minsk : Minstrojarhitektury, 2010. - $110 \mathrm{~s}$.

2. Ogarkov, B. I. Teoriya deformirovaniya drevesnyh materialov s uchetom polzuchesti / B. I. Ogarkov // Issledovaniya v oblasti drevesiny i drevesnyh materialov Tr. In-ta lesa i drevesiny SO AN SSSR Krasnoyarsk, 1967. - S. 130-139.

3. Kravchuk, A. S. Mekhanika polimernyh i kompozicionnyh materialov. Eksperimental'nye i chislennye metody / A. S. Kravchuk, V. P. Majboroda, YU. S. Urzhumcev. - M.: Nauka, 1985. - 304 s.

4. Narisava, I. Prochnost' polimernyh materialov / I. Narisava. - M.: Himiya, 1987. - $400 \mathrm{~s}$.

5. Ivanov, YU. M. Energiya aktivacii razvitiya u orientirovannogo zhestkocepnogo polimera vynuzhdennoj elasticheskoj deformacii $/$ YU. M. Ivanov // Vysokomolekulyarnye soedineniya. - 1984. - t. 26B№6. - S. 425-430.
6. Ivanov, YU. M. Predel plasticheskogo techeniya drevesiny / YU. M. Ivanov. - M. : Gosstrojizdat 1948. - 223 s.

7. Ivanov, YU. M. K issledovaniyu vysokoelasticheskogo sostoyaniya drevesiny / YU. M. Ivanov. - Tr. In-ta lesa i drevesiny SO AN SSSR, 1962. - T. 51. - S. 78-89.

8. Belyankin, F. P. Dlitel'noe soprotivlenie dereva / F. P. Belyankin // ONTI. - M. : Nauka, 1934. - $416 \mathrm{~s}$.

9. Belyankin, F. P. Deformativnost' i soprotivlyaemost' drevesiny / F. P. Belyankin, V. F. YAcenko. - K.: Iz-vo AN USSR, 1957. - $86 \mathrm{~s}$.

10. Ugolev, B. N. Deformativnost' drevesiny i napryazheniya pri sushke / B. N. Ugolev. - M., 1971. - $174 \mathrm{~s}$.

11. Leont'ev, N. L. Dlitel'noe soprotivlenie drevesiny / N. L. Leont'ev. - M. : Goslesbumizdat, 1957. $-132 \mathrm{~s}$.

12. Ivanov, YU. M. Dlitel'naya prochnost' drevesiny / YU. M. Ivanov /I Lesn. zhurn. - 1972. - № 4.- S. 76-82.

13. Ogarkov, B. I. Teoriya uprugogo posledejstviya drevesiny // B. I. Ogarkov / «ZHurnal tekhnicheskoj fiziki». - 1957. - T. 27. - S. 70-82.

14. Lyuboshic, M. I. Vliyanie skorosti ispytaniya na predel plasticheskogo techeniya drevesiny sosny //Avtoreferat diss., kand. tekhn. nauk. Minsk, 1950. - $16 \mathrm{~s}$.

15. Konstrukcii derevyannye. Drevesina konstrukcionnaya cel'naya i kleenaya mnogoslojnaya. Opredelenie nekotoryh fizicheskih i mekhanicheskih svojstv. STB EN 408-2012.- Vved. 20.04.2012 - Minsk. : Gosstandart, 2012-22 s.

16. Evrokod. Osnovy proektirovaniya stroitel'nyh konstrukcij: TKP EN 19902011* (02250). - Vved. 15.12.11. - Minsk : Min-strojarhitektury, 2011. $94 \mathrm{~s}$.

17. Meshyk, A., Barushka, M, Marozava, V. (2020) Snow as a Contributor to Spring Flooding in Belarus. Environmental Science and Pollution Research. 1-11. https://doi.org/10.1007/s11356-020-09638-8.

18. Drevesina konstrukcionnaya. Klassy prochnosti. STB EN 338-2011. Vved. 28.10.2011 - Minsk. : Gosstandart, 2011. - 7 s.

19. Konstrukcii derevyannye. Drevesina kleenaya mnogoslojnaya. Klassy prochnosti i opredelenie harakteristicheskih znachenij. STB EN 11942011. - Vved. 25.11.2011 - Minsk. : Gosstandart, 2011 - 9 s.

Материал поступил в редакцию 13.02.2021 